\title{
Lectura, Iglesia y sociedad
}

Reading, Church and society

\author{
Dr. Pedro C. Cerrillo Torremocha \\ Área de Didáctica de la Lengua y la Literatura. \\ Univesidad de Castilla la Mancha. CEPLI \\ pedrocesar.cerrillo@uclm.es \\ Arantxa Sanz Tejeda \\ Univesidad de Castilla la Mancha. CEPLI
}

\section{Resumen}

La lectura es una herramienta muy importante para las sociedades. Por eso, desde hace muchos siglos gobiernos y poderosas instituciones han controlado lo que la gente podía leer, descatalogando obras que hacían lectores libres y competentes en pos de aquellas que actuaban como catalizador de determinadas ideologías. En la literatura infantil también.

\begin{abstract}
Lecture is a very important tool for societies. Therefore, for many centuries, governments and powerful institutions have controlled what people could read, uncataloging books that were critical readers and encouraging those who passed certain ideologies. Children's literature too.
\end{abstract}

Palabras clave: Lectura, Censura, Literatura Infantil y Juvenil

Keywords: Reading, Censorship, Children’s Literature

\section{Introducción}

La historia nos indica que en los momentos en que autoridad religiosa y civil se han unido, el poder se ha ejercido con mayor fuerza - injustificada y desproporcionada-, siendo perceptible en todos los ámbitos cívicos, también en la lectura, privilegiando autores y obras que transmitían las ideas del propio poder, y persiguiendo literatura que esas autoridades catalogaban como "poco recomendable", aplicando la máxima maquiavélica de que "el fin justifica los medios". Lectura, iglesia y sociedad, en esos casos, aparecen unidas por numerosas arbitrariedades e injusticias, que han afectado gravemente solo a la primera de ellas, la lectura (libros, escritores, ilustradores, editoriales y lectores) que las sufre como víctima.

La censura, en una forma u otra, es el corolario de todo poder, y la historia de la lectura se ilumina con una hilera, en apariencia interminable, de hogueras encendidas por los censores, desde los rollos de papiros más antiguos hasta los libros de nuestro tiempo (Manguel, 1998, p. 316).

Quemas y destrucciones de libros, así como persecuciones de escritores, han sido constatadas en el pasado en China, en Egipto, en Grecia, en el Imperio Romano... 
Aunque no hay testimonios directos, parece ser que los persas destruyeron un archivo de casi 20.000 rollos de papiro que Ramsés II (siglo XIII a.C.) ordenó reunir para ser albergados en un espacio propio. Es cierto que muchas de aquellas antiguas destrucciones de libros se hicieron más por ignorancia que por ánimo censor:

Cuántos cientos de miles de manuscritos se abandonaron a la decrepitud por pura ignorancia, como la colección de obras literarias antiguas de un contemporáneo de Ramsés II, que pasaron por las manos de cinco cuidadosos herederos hasta que el último, un carpintero, arrancó las hojas - en especial del precioso Libro de los sueñospara escribir en el dorso su correspondencia comercial (Polastron, 2007, p. 13).

Pero también es cierto que la máxima, quizá nunca escrita, que dice que "los libros de mis enemigos son mis enemigos" se ha cumplido con notable exactitud en muchos momentos de la historia. Uno de los ejemplos más significativos es el de la Gran Biblioteca de Alejandría (fundada en el siglo III a.C., llegando a albergar -según algunas estimaciones- casi un millón de manuscritos), que fue completamente destruida a finales del siglo III d.C., con los saqueos ordenados por Aureliano (en el año 273), primero y, luego, por Diocleciano (en 297); bastantes años antes ya había sufrido otro expolio cuando Julio César (año 48 a.C., dos antes de tomar la ciudad) ordenó un incendio que minara a la flota enemiga; un fuego que, avivado por el viento, alcanzó la biblioteca, desapareciendo miles de originales (entre ellos, textos de Homero e Hipócrates, o algunas de las mejores tragedias de diversos escritores griegos). En cualquier caso, en la Roma anterior a Cristo, la censura era algo habitual (Vid. Polastron, 2007: 29), tanto allí como en los territorios conquistados: en Cartago, p.e., Publio Cornelio Escipión (siglo II a.C.) ordenó la destrucción de los libros escritos en cualquier lengua que no fuera el griego.

En la antigüedad, la religión fue motivo para la destrucción de libros. Durante el periodo de las persecuciones contra los cristianos, Galerio Maximiano (emperador romano en los primeros años del siglo IV), con la ayuda de Diocleciano, ordenó que los textos de los profetas fueran quemados. Luego, cuando el cristianismo se proclamó religión oficial del Imperio con Teodosio (Edicto de Tesalónica, a. 380), el paganismo fue perseguido, incluyendo en la persecución los textos que no respondían al ideario cristiano. Algo parecido ha sucedido con los musulmanes o con los judíos, probablemente, porque como dice Polastron (2007, p. 34), las religiones suelen estar gobernadas por "gente de un solo libro, convicción que implica a menudo la destrucción de todos los otros [libros]". A partir del siglo XII, la preocupación tanto de la Iglesia como del Estado giró en torno a la herejía, entendida esta como aquellas tendencias que se oponían al dogma dominante, la religión Católica. Los estragos causados por los cátaros en el norte de Italia y en el mediodía francés sembraron el pánico entre los jefes de la cristiandad (Vid. Sánchez, 2005, en línea).

\section{Inquisición, imprenta y censura}

Con los nombres de Inquisición y Santa Inquisición conocemos la institución, creada por la Iglesia Católica para vigilar y perseguir las conductas heréticas. Aunque en la Edad Media se creó en el Languedoc una Inquisición (1184) y en 1249 se implantó en el reino de Aragón, fue con los Reyes Católicos y la unión de los reinos 
de Aragón y Castilla cuando se creó la Inquisición Española (Santa Inquisición, 1478, por bula del Papa Sixto IV), bajo control directo de la monarquía española, extendiendo su actividad a muchos ámbitos de la vida privada, y llevando la institución a los países conquistados en América.

La Inquisición también intervino en el control de las publicaciones impresas, porque entendió que eran un importante medio para la difusión de todo tipo de ideas. Se estableció que los libros necesitaban una autorización previa del Consejo Real y, posteriormente, tras el correspondiente examen, la aprobación del Santo Oficio. Con el fin de controlar todas las publicaciones surgió en 1559 el Index Librorum Prohibitorum (con el inquisidor Valdés como principal inspirador), al que siguieron al menos cuarenta ediciones más. Los índices inquisitoriales españoles prohibían algunas obras absolutamente (in totum), mientras otras lo eran parcialmente (donec corrigatur), es decir hasta que fueran corregidas o expurgadas, suprimiéndose los pasajes catalogados como "peligrosos"; esta segunda modalidad posibilitó los "índices expurgatorios" que permitían la lectura de las obras parcialmente mutiladas. Los autores prohibidos no eran los mismos en todos los países en los que intervenía la Inquisición, pues los niveles de tolerancia eran diferentes. En ocasiones se toleraban ciertos aspectos o simplemente pasaban desapercibidos ante los ojos del censor, pero generalmente no se permitió nada que pudiese dar lugar a confusión respecto al dogma (Vid. Escudero, 1985, pp. 36-38).

La implantación y extensión de la imprenta por la mayoría de los países europeos (entre 1436 - Alemania - y 1487 - Portugal —, habían aparecido las primeras imprentas en Italia -1465-, Francia - 1470 - Hungría - 1473 - España - 1475- e Inglaterra —1477-), facilitó la "institucionalización" de la censura. La aparición en Roma, en 1559, bajo control - precisamente- de la Inquisición, del ya mencionado Index Librorum Prohibitorum et Expurgatorum, hizo que, entre otros y en diversos momentos, textos ya editados de Erasmo, La Fontaine, Montesquieu, Copérnico, Descartes, Zola o Balzac fueran prohibidos. Aquel Índice, supervisado con "cuidado celo" por la Sagrada Congregación de la Inquisición — cuyos responsables, además de prohibir determinadas ediciones, censuraban libros antes de publicarse y eliminaban pasajes que consideraban perniciosos para la autoridad eclesiástica—, se editó en diferentes ocasiones durante casi cuatrocientos años, entre 1559 y 1948; la última edición, que el Vaticano mantuvo vigente hasta 1966 —en que fue abolido ese Índice maldito - incluía todavía la prohibición de leer, bajo pena de excomunión, a Spinoza, Voltaire, Colette, Graham Greene o Sartre, por citar algunos ilustres escritores o pensadores; L'Observatore Romano publicó el 15 de junio de 1966 un comunicado de la Sagrada Congregación para la Doctrina de la Fe en el que se daba por preabolido el Index, aunque se advertía que, sin ser fuerza de ley, sí tenía autoridad moral, pues había libros que "podían dañar la fe y las costumbres". El objetivo de aquellas primeras censuras institucionalizadas fue religioso, derivado del deseo de mantener una "ortodoxia" doctrinal (en realidad, un control) en unos momentos en que se estaban produciendo en buena parte de Europa importantes contestaciones en el seno de la Iglesia. Lo que sucede es que, casi desde el primer momento, ese control y, por tanto, aquella censura, se extendió también a la literatura popular impresa de asuntos profanos: de otro modo no podríamos explicar la inclusión en el índice de libros prohibidos del inquisidor Valdés, de varios libros de juegos, entre ellos un libro del que no conocemos a su autor - aunque atribuido a Lorenzo Spirito-, el Libro del juego de las suertes, 
editado en Valencia en 1528, en el que se hacían preguntas sobre aspectos de la vida, con respuestas en tono de burla y finalidad de puro juego.

En los albores del siglo XVI la Inquisición era un actante político de primer orden, había logrado elevadas cuotas de poder, aprovechando la coyuntura del absolutismo monárquico y realizando todo tipo de tretas. En todas las monarquías de la Europa del Antiguo Régimen, y, por ende, en la España de los Austrias, la identificación de política y religión era total (Piorno, 2015, pp.12-15). Así pues, Felipe II en un intento de controlar las opiniones escritas que transitaban por sus reinos dictó una ley de censura en 1558 - algo que ya habían intentado de forma infructuosa los Reyes Católicos-. A tales efectos, se prohibía la introducción de libros escritos en castellano e impresos en el extranjero (incluyendo Aragón, Navarra, Valencia y Cataluña) que no contasen con licencia previa. El escribano de Cámara estaba obligado a rubricar cada hoja del original presentado a la imprenta para evitar su modificación, y a validar con su firma cada tachadura. En el momento de la impresión, el librero debía aportar el original y dos volúmenes que posteriormente serían cotejados por el Corrector General - la única persona con potestad para autorizar su venta- Sin embargo, el Inquisidor General y los obispos podían imprimir sin licencia. Además, tanto las autoridades civiles como las religiosas tenían encomendada la labor de visitar asiduamente librerías y bibliotecas particulares -inclusive las de conventos y monasterios-, para comprobar que no albergaban libros censurados.

Hasta aproximadamente 1740, en España hubo autos de fe. A partir de ahí, el complejo entramado de la Inquisición empezó a decaer; las condenas a muerte cesaron, los autos perdieron suntuosidad y el prestigio del personal inquisitorial fue disminuyendo. Paralelamente, el ejercicio contra la herejía se centró en la cultura escrita, vía principal por la que circulaba la renovación del pensamiento.

Melchor de Macanaz, fiscal de Castilla en tiempos de Felipe V, pretendió acotar el Tribunal de la Inq<isición y supeditarlo a la autoridad del Consejo de Castilla. De este modo, los monarcas designarían a los calificadores de libros y no se podían prohibir obras sin antes comunicarlo a la Corona. A consecuencia de ello, en 1715 sufrió un proceso inquisitorial y tuvo que huir a Francia (Bianchi, 2002, p. 66).

La principal función de la Inquisición en el siglo XVIII fue la censura de libros. En este fragmento, Diego de Torres Villarroel (1972, pp. 194-197) relata cómo la retractación del reo y su declaración de ignorancia le libraban de la pena, poniendo de manifiesto los síntomas de decadencia de la institución.

Yo entraba a cumplir con el precepto de la misa en una de las iglesias de Madrid; y cuando quise doblar las rodillas para hacer la reverencia y postración que se acostumbra entre nosotros, me arrebataron la acción y los oídos las voces de un predicador que desde el púlpito estaba leyendo, en un edicto del santo tribunal, la condenación de muchos libros y papeles; y mi desgracia me llevó al mismo instante que gritaba mi nombre y apellidos y las abominaciones contra un cuaderno titulado Vida natural y católica, que catorce años antes había salido de la imprenta. [...] Sonsaqué a mi conciencia y pregunté a mis acciones, y no percibí en ellas la más leve nota que pudiese agear el semblante de la verdadera ley que he profesado con todos los míos; y viéndome libre de malas razas, de delitos y fealdades propias y ajenas, me afirmé con resolución 
en que yo no podía ser notado más que de bobo o ignorante, y en esta credulidad hallé el desahogo de la mayor parte de mis congojas. Yo quedé sumamente consolado, porque ser necio, ignorante o descuidado, no es delito, y donde no hay delito, no deben tener lugar las afrentas y las pesadumbres; además, que estas condenaciones han cogido y están pescando cada día a los sabios más astutos y a los varones más doctos, y sobre éstos regularmente se arrojan las advertencias y los recogimientos; que a los que no escriben libros, jamás se los recoge tribunal alguno; siendo creíble que muchos cuadernos se mandan retirar, no por castigo de los autores, sino por no exponerlos a la malicia de los que los suelen leer. [...]

Determiné manifestar al santo consejo, en un reverente memorial, mi desgraciada inocencia, rogando por él, con humildes súplicas, que me declarase la temeridad de mis proposiciones, sólo para huirlas y blasfemarlas; y que mi ánimo no era darles defensa con la explicación, ni disculpa con el discurso de algún nuevo sentido, ni las deseaba otra inteligencia que la que había producido su condenación; porque nada me importaba tanto como salir de mis errores, aborrecer mis disparates y rendir toda mi obediencia a sus determinaciones y decretos. Examinaron los piadosos ministros mi sencillez, mi cristiana intención y las ansias de mi católico deseo, y a los quince días me volvieron el libro, el que imprimí por segunda vez, juntamente con el memorial presentado y un nuevo prólogo [...] Conseguí con estas desgracias aumentar la veneración a este santo y silencioso tribunal, acordarme sin tanto susto de aquel miedo que producen las máximas de su rectitud, y perder aquel necio horror que había concebido de que mis obras fuesen a su castigo y residencia.

\section{Iglesia y censura en la España franquista}

La victoria en la Guerra Civil española del llamado "Bando Nacional", es decir de los militares sublevados, supuso también el triunfo de la España Católica, de modo que el catolicismo se convirtió en la única religión oficial del Estado, recuperando la Iglesia Católica todos los privilegios institucionales que tuvo en otras épocas y logrando otros más que le permitieron, a cambio de su apoyo al gobierno franquista, imponer su monopolio religioso.

\section{El Gabinete Santa Teresa y la censura de LIJ}

Fueron numerosos los decretos, órdenes y leyes que, tras el fin de la Guerra Civil, regularon y administraron las prácticas censoras en la España franquista, pero nos referiremos aquí a una institución singular, el Gabinete de lectura Santa Teresa de Jesús, creado en 1940 por el Consejo Superior de Mujeres de Acción Católica. Esta agrupación religiosa se dedicó, entre otras cosas, a la crítica de libros infantiles y juveniles, indicando qué debían leer y qué no los niños españoles durante muchos años. Una de sus miembros, Montserrat Sarto, periodista, especialista en temas de lectura y literatura infantil y juvenil, y asesora sobre estos asuntos para diversos organismos desde los años cincuenta del pasado siglo, habla sobre el Gabinete en uno de los interesantes documentos de su archivo personal custodiado en la Biblioteca de la Facultad de Formación del Profesorado y Educación de la Universidad Autónoma de Madrid. En él explica que el Gabinete reunió más de 12.000 fichas crítico-bibliográficas, clasificadas por materias y grupos de edades, en las que se especificaba además la conveniencia o no 
de su lectura. "Para realizar esta labor - continúa Sarto - el Gabinete tiene un cuadro de lectoras-especialistas, en su mayoría bibliotecarias, escritoras, maestras, madres de familia, etc.". De entre todas, y según se desprende de los archivos de censura que se conservan en el Archivo General de la Administración (AGA) en Alcalá de Henares, destacaron por su "ardor crítico" María Isabel Niño, María África Ibarra y la propia Montserrat Sarto, entre otras. En 1966, fecha del documento mencionado, habían publicado ya seis Catálogos patrocinados por la Dirección General de Archivos y Bibliotecas, a través del Servicio Nacional de Lectura, y formaban parte de la Comisión de Información y Publicaciones Infantiles del Ministerio de Información, organismo que autorizaba o no la publicación de los libros que se presentaban al trámite de censura. Cada libro se analizaba atendiendo a su tema, carácter literario, moral, presentación y adaptación a determinada edad y, posteriormente, la lectora completaba una ficha dando respuesta a todas las preguntas formuladas. Cada obra era leída por dos personas y, del consenso de ambas, salía la redacción definitiva de las fichas bibliográficas y los comentarios relativos a la conveniencia, o no, de su lectura.

El primer volumen del Catálogo crítico de libros para niños (1945) recogía el análisis de 900 libros realizados por este Gabinete, divididos en cuatro bloques por grupos de edad ( 3 a 6 años, 6 a 9, 9 a 12 y 12 a 15). Dentro de cada categoría etaria se presentaban los respectivos libros con un breve resumen, indicación de los temas tratados y su clasificación de acuerdo a la siguiente calificación (Gabinete, 1945, s./ p.):

a. Recomendables: Los de reconocido mérito y moralidad.

b. Aceptables: Los que, sin alcanzar el grado anterior, pueden ponerse en todas las manos, aunque algunos exigen cierta cautela por los reparos que oportunamente se indican.

c. Tolerables: Los que se pueden permitir a determinados lectores, dadas sus circunstancias, sin autorizar su lectura a la generalidad.

Al final, se recoge aún una cuarta categoría: Inconvenientes. En ella se incluyen los libros considerados impropios para niños, aun cuando hayan sido escritos expresamente para ellos.

Dicha clasificación la realizaban, como se puede imaginar, en función de aspectos religiosos — principalmente-, morales, patrióticos y artístico-literarios, no siendo extraño encontrar contradicciones o ambigüedades en cuanto a qué era considerado aceptable o adecuado para niños y jóvenes. Por ejemplo se reconocía que la violencia era aceptable en los textos infantiles siempre que se utilizara en contextos ortodoxos, lo que explicaría que las historias de los mártires cristianos fueran recomendadas calurosamente y que no aparecieran objeciones a los pasajes en los que se describía el martirio. Así aparece en El verdugo de su hijo: Martirio de los primeros cristianos de Uganda, que en aquella primera edición del Catálogo (1945, p. 137) era calificado como "altamente moralizador y ejemplar". Sin embargo, la violencia fue uno de los reparos más frecuentes para desaconsejar la lectura de otras obras, especialmente las de autores extranjeros, como algunos cuentos de los hermanos Grimm o Perrault, tildados de violentos; hasta Hansel y Gretel fue objetado por "poco recreativo por su desagradable asunto", o la Caperucita Roja de Perrault por contener "detalles desagradables y un desagradable final" (1945, pp. 49 y 57). 
En aquellos catálogos se recomendaban las adaptaciones de libros de caballerías, biografías históricas y novelas de tema español y se proponía un plan de edición de clásicos expurgados para la juventud que debían ajustarse a la ideología imperante. El Catálogo crítico de libros para niños era un instrumento que intervenía en la censura de forma secundaria, pero que influía en la selección de lecturas para niños que los padres y otros adultos mediadores realizaban. Ese ánimo de influir en las lecturas de la sociedad se refleja incluso en las palabras de Jesús Enciso, Consiliario del Consejo Superior de Mujeres de Acción Católica, que escribe el prólogo de esa primera edición:

\begin{abstract}
A los papás y a los Reyes [Magos], y a los directores de escuelas y bibliotecas y catecismos, les conviene saber qué libros gustan a los niños de las distintas edades. Esto es lo que ha hecho el Consejo Superior de Mujeres de Acción Católica con su CATÁLOGO CRÍTICO DE LIBROS PARA NIÑOS. (...) no te olvides de darlo a conocer en todas partes. Con ello harás una obra de apostolado en favor de los niños; de esos niños "cuyos ángeles ven siempre la cara de mi Padre que está en los cielos" (Mt. 18, 10) y de quienes dijo Jesús que "a quien les escandalizare, más le valía que le atasen al cuello una piedra de molino y lo arrojasen al mar (Mt. 18, 6)". (Gabinete, 1945, s/p)
\end{abstract}

Eso fue posible porque la Iglesia Católica constituía el principal pilar institucional e ideológico del régimen franquista, y la gran defensora de las políticas gubernamentales por las que se suprimió la coeducación y pasó a considerarse superflua la educación para las mujeres una vez realizada la Educación Primaria.

Ya en la posguerra, en la década de los 50, la producción literaria que llegaba a nuestro país desde Europa era prácticamente nula, pues se creía que era una literatura de corte realista y liberal, lo que no gustaba a los que gobernaban bajo los postulados del "pensamiento único". La LIJ de la España de posguerra era poco relevante: por un lado, por el aislamiento del país respecto a la literatura para niños y jóvenes que se hacía en otros países (piénsese que Pippi Calzaslargas, aparecida en Suecia en 1945, tuvo la primera edición española en 1961); por otro, porque muchos de los grandes cuentos de tradición popular eran vistos por los censores como problemáticos para la educación de niños y jóvenes (algo de lo que no se libraron ni Perrault ni los hermanos Grimm); y, finalmente, porque los grandes renovadores de la LIJ española - renovación en temas, en formas y en estética, que se había producido en los años de la $2^{\mathrm{a}}$ República - se vio truncada con la partida hacia el exilio de escritores como Manuel Abril, Antoniorrobles, Bartolozzi, $\mathrm{M}^{\mathrm{a}}$ Teresa León, Magda Donato o Elena Fortún; y de ilustradores como Elvira Gascón, Ramón Peinador, José Bardasano o Ramón Gaya.

El carácter didáctico y doctrinal de la LIJ de posguerra era su nota más relevante, de modo que en la selección de lecturas para niños predominaban algunos libros educativos y moralizantes, cuentos maravillosos, traducciones o adaptaciones de algunos clásicos, selecciones dirigidas en las que se incluían libros que no fomentaban la creatividad ni el pensamiento crítico de los niños de época y que, en ocasiones, les sustraían el derecho a la fantasía.

La iniquidad de todas las censuras ha afectado durante todo el siglo XX a la LIJ. Cuando Getulio Vargas - presidente constitucional de Brasil- dio un autogolpe de estado en 1937, Capitanes de arena de Jorge Amado fue pasto de las llamas en Bahía, por ser un peligroso vehículo para la transmisión de ideas progresistas al relatar la dura 
vida de los niños brasileños sin hogar. Los regímenes dictatoriales de la Alemania nazi y la Italia fascista también afectaron a la literatura para niños y jóvenes, no solo por las prohibiciones expresas de libros, sino por infringir "castigos" a las editoriales con la retirada de cupos de papel. También, en el caso de dictaduras de derechas, tales como la URSS o las actuales Cuba y Venezuela, la LIJ ha sido utilizada como un poderoso medio por el que se transmitían ideas afines al régimen. En la dictadura argentina de Videla cientos de libros infantiles fueron prohibidos por un "exceso de fantasía", un elemento que podía ser perturbador para la infancia, El árbol de Bartolo (Laura Devetach) o Un elefante ocupa mucho espacio (Elsa Bornemann), incluso libros de otras épocas, como El Principito. Cabe señalar que también se prohibía la lectura de libros cuyo autor se había exiliado de su país. En España, en 1945, Celia institutriz en América fue retirada de las librerías porque su autora, Elena Fortún, estaba exiliada en Argentina.

El cuidado ante ciertos temas - considerados "tabúes"- y las presiones sociales o institucionales para silenciar determinados libros provocan la autocensura de algunos autores. Es lo que conocemos como censuras soterradas. Estas censuras tienen como base la consideración de la infancia como una etapa cándida e inocente que debe ser protegida de ciertos temas y usos del lenguaje del mundo adulto, ya que, los que dirigen la educación de los niños, se preocupan más por controlar los conocimientos que se les transmiten que por su formación integral como personas. La Asociación Americana de Bibliotecarios difunde cada año una lista con los diez libros que más peticiones tienen para ser retirados de las bibliotecas públicas, en una censura soterrada ejercida por instituciones o asociaciones de diverso tipo. El libro con más denuncias desde hace unos años, es Tres con Tango, una historia de amor verídica entre dos pingüinos macho del zoo de Central Park, que, observan con atención cómo las parejas heterosexuales incuban sus huevos y, ante la imposibilidad biológica de tener descendencia, deciden hacer lo mismo con una piedra. Este álbum ilustrado publicado en abril de 2005 ha suscitado la crítica de numerosos padres que han pedido que su lectura se realice bajo la supervisión de un adulto, llegando a ser eliminado de las estanterías de bibliotecas y librerías

Es una censura moderna y sofisticada que no prohíbe explícitamente las obras pero las relega a rincones impracticables en las estanterías. Otros ejemplos de LIJ objetados con argumentos absurdos son:

- En las bibliotecas de EE.UU, El guardián entre el centeno de J. D. Salinger por la rebeldía manifiesta del adolescente protagonista Holden Caulfield o la Bella durmiente por ser una historia que puede causar susto en los niños.

- Harry Potter ha estado censurado durante muchos años, porque las autoridades veían en él una defensa de los valores de la brujería.

- En la provincia china de Hunan, Alicia en el País de las Maravillas porque daba cualidades a los animales que les permitían actuar como personas.

- En diversos países James y el melocotón gigante de Roal Dahl por usar un lenguaje inapropiado para niños. (Vid. Cerrillo 2015, pp. 54-60)

Quienes cercenan las libertades de las personas suelen emitir órdenes de prohibición de lecturas más pronto que tarde, porque saben que la lectura aporta al lector criterio propio, capacidad para el juicio crítico, conocimiento del mundo. Por eso, no dudan en 
utilizar diversos tipos de estrategias y recursos que les permitan ocultar y prohibir determinados libros, así como perseguir y condenar a escritores y lectores: la censura, la apelación a la moral establecida, las doctrinas emanadas del poder, el pensamiento único (...) Cuando eso sucede, si algo de ello no se respeta se ponen en marcha mecanismos "correctores": persecución, condenas, secuestros, aislamiento, cárcel, incluso la muerte.

La humanidad debe reivindicar, a través de sus instituciones democráticas, la libertad de las personas en toda su dimensión, también la libertad para leer cualquier libro, porque es un derecho y porque, en muchos casos, se ha demostrado que es una forma de resistir a los poderes autárquicos y de apartarse de dogmatismos y doctrinas impuestas.

Muchas veces nos hemos preguntado la razón por la que los gobiernos totalitarios de todo el mundo han considerado que la lectura es una actividad peligrosa a la que intentan someter a un estricto control (Vid. Cerrillo, 2010). Solo se nos ocurre como respuesta que, quizá, se deba a que entienden que la lectura proporciona libertad personal, juicio crítico y opinión propia a quien la practica asiduamente. Los índices de libros prohibidos de la Inquisición, los atentados islamistas, las quemas de libros de los nazis, las censuras y secuestros franquistas, las persecuciones stalinianas, las represiones castristas, las prohibiciones de Pinochet o Videla, son varios ejemplos de que para quienes ejercen el poder autárquicamente la lectura es un peligro, porque siempre han creído que los libros pueden cambiar la vida y, sobre todo, el pensamientos de sus lectores.

Los censores - los inquisidores-, aunque peligrosos, suelen ser personas bastante estúpidas, muy ingenuas, que creen que pueden medirlo todo y controlar la historia (...) Los censores no piensan mucho. Son elementales y facciosos (Montes, 2003, pp. 107 y 108).

Aunque la literatura, en muchas ocasiones, ha sido un instrumento que ha servido para adoctrinar o moralizar, sobre todo en la infancia y la adolescencia, han sido los lectores, con su aprobación o su rechazo, quienes han seleccionado y, por tanto, perpetuado lo que más les ha interesado: ¿qué ha quedado hoy de aquellas lecturas obligatorias, como La buena Juanita, que, durante muchos años del siglo XX sirvieron para transmitir a las niñas españolas un modelo de mujer sumiso y discriminado? Por fortuna, muy poco; frente a ese modelo de niña, han pervivido otros, como Pippi o Celia (esta pese al exilio de su autora, Elena Fortún, y la prohibición de editar sus libros durante muchos años de la España franquista) — más recientemente, Matilda - en quienes se unían la imaginación y la espontaneidad de unas niñas que no terminaban de entender el mundo de sus mayores (Vid. Cerrillo, 2015, p. 61).

\section{Referencias Bibliográficas}

Bianchi, D. (2002). Inquisición e Ilustración. Un expediente reservado a José del Campillo, Investigaciones históricas: Época moderna y contemporánea, 22, 63-82. [En línea] Disponible en http://cort.as/qEAK [Consultado el 7 de marzo de 2016].

Cerrillo, P. C. (2010). La lectura prohibida. En Sobre lectura, literatura y educación (pp. 59-86). México, D.F.: Miguel Ángel Porrúa Editor.

- (2015). Literatura, siempre. Santander: Ediciones Universidad de Cantabria. 
Escudero, J. A. (1985). La Inquisición en España, Cuadernos Historia, 16, 1-39. [En línea] Disponible en http://cort.as/qEAD [Consultado el 2 de abril de 2016].

Gabinete de Lectura Santa Teresa de Jesús, (1945). Catálogo crítico de libros para niños. Madrid: Consejo Superior de Mujeres de Acción Católica.

Manguel, A. (1998). Una historia de la lectura. Madrid: Alianza.

Montes, G. (2003). Literatura para chicos y adolescentes: obras censuradas y temas prohibidos. En A. Ma Machado y G. Montes, Literatura infantil: creación, censura y resistencia (pp. 107-112). Buenos Aires: Sudamericana.

Ortiz, M. (2005). Iglesia y control social. De controladora a controlada. En J. de la Cueva Merino y Á. L. López Villaverde (Coord.), Clericalismo y asociacionismo católico en España: de la Restauración a la Transición. Un siglo entre el Palio y el Consiliario. Cuenca. UCLM.

Piorno, R. (2015). La fe como arma política. Al servicio de la monarquía, Muy historia, $68,12-15$.

Polastron, L. X. (2007). Libros en llamas. Historia de la interminable destrucción de bibliotecas. México: Fondo de Cultura Económica y Libraria.

Sánchez, J. (2005). Los orígenes de la Inquisición Medieval, Clio \& Crimen, no 2, 1752. [En línea] Disponible en http://cort.as/qEA- [Consultado el 2 de abril de 2016].

Torres, D. (1972). Vida, ascendencia, nacimiento, crianza y aventuras. Madrid: Clásicos castellanos. 